DIW BERLIN

Discussion Papers

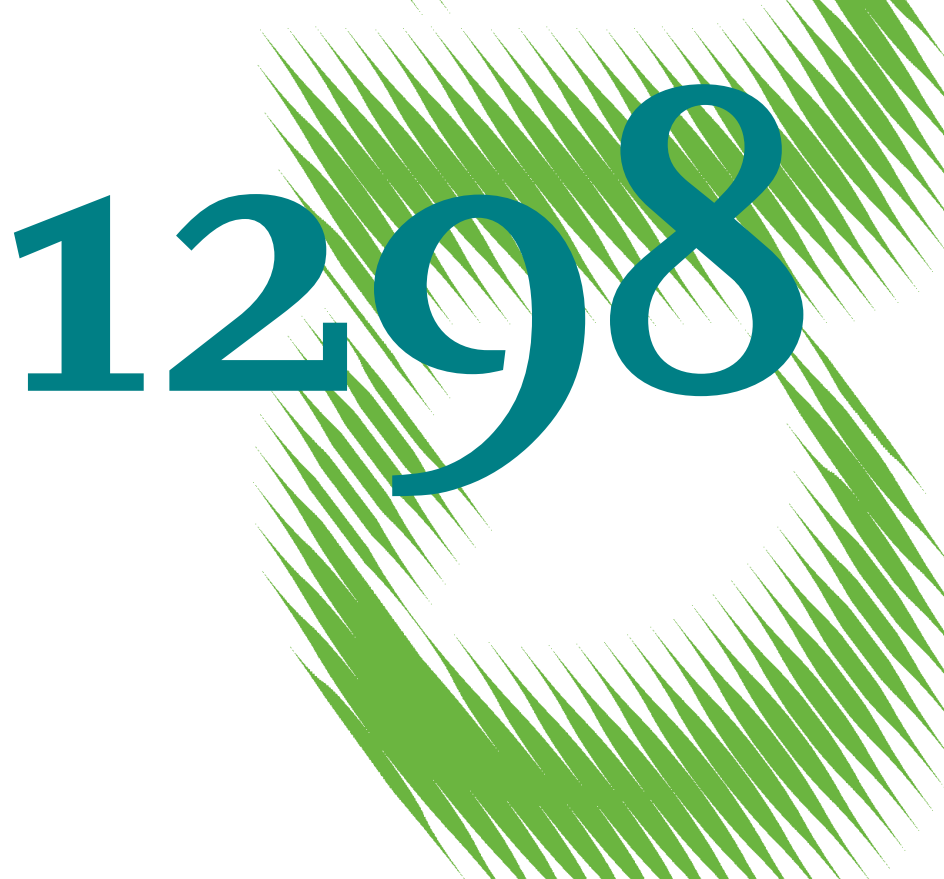

The Benefit of Coordinating Congestion Management in Germany 
Opinions expressed in this paper are those of the author(s) and do not necessarily reflect views of the institute.

IMPRESSUM

(C) DIW Berlin, 2013

DIW Berlin

German Institute for Economic Research

Mohrenstr. 58

10117 Berlin

Tel. $+49(30) 89789-0$

Fax +49 (30) $89789-200$

http://www.diw.de

ISSN print edition $1433-0210$

ISSN electronic edition 1619-4535

Papers can be downloaded free of charge from the DIW Berlin website:

http://www.diw.de/discussionpapers

Discussion Papers of DIW Berlin are indexed in RePEc and SSRN:

http://ideas.repec.org/s/diw/diwwpp.html

http://www.ssrn.com/link/DIW-Berlin-German-Inst-Econ-Res.html 


\title{
The Benefit of Coordinating Congestion Management in Germany*
}

\author{
Friedrich Kunz ${ }^{\dagger} \quad$ Alexander Zerrahn ${ }^{\ddagger}$
}

May 13, 2013

The management of congestion within the German electricity transmission network has become more important during the last years. This emerging relevance is caused by the increase of renewable generation and the partial phaseout of nuclear power plants. Both developments yield a change in the transmission flow pattern and thus the need for congestion management. Currently, four German transmission system operators (TSOs) are in charge of managing congestion using curative methods, particularly re-dispatch of power plants. However, the existence of four TSOs within Germany induces the question whether coordination between them in managing national congestion would be beneficial. To address this issue, we apply a generalized Nash equilibrium model to analyze different degrees of coordination, covering the German electricity market with a detailed representation of the generation and network structure. Our results indicate that the costs of congestion management decrease in a rising degree of coordination as TSOs take into account congestion in other operators' zones. Total costs are highest in case each TSO is solely responsible for its own zone, and lowest if one integrated entity is in charge of mitigating congestion. We conclude that, in a setup with multiple TSOs, inducing coordination, for instance through a common market, has the potential of lowering the overall costs of congestion management.

JEL Codes: C61, L94, Q40

Keywords: Congestion Management, Coordination, Electricity Economics, Generalized Nash Equilibrium, Germany

${ }^{*}$ The authors would like to thank Daniel Huppmann, Thure Traber, and Christian von Hirschhausen for valuable comments. Friedrich Kunz acknowledges the financial support by the Mercator Foundation.

${ }^{\dagger}$ German Institute for Economic Research (DIW Berlin), Mohrenstr. 58, D-10117 Berlin, fkunz@diw.de

${ }^{\ddagger}$ German Institute for Economic Research (DIW Berlin), Mohrenstr. 58, D-10117 Berlin, azerrahn@diw.de 


\section{Introduction}

Incorporating increasingly higher shares of renewables in the German electricity generation portfolio demands adjustments in the entire electricity system. For instance, markets and their underlying procedures are required to be redesigned to allow for the integration of intermittent generation. Furthermore, transmission of electricity to load centers becomes more important. Firstly, the geographical location of renewable resources - in particular wind and solar - and thus their spatial generation pattern depends on natural conditions. Secondly, renewable capacities are installed in a more decentralized fashion than conventional thermal generation units. Both aspects result in new requirements on the transmission network to transport electrical energy from generation to load centers. In the long term, the flexibility of reshaping the transmission infrastructure allows to meet the upcoming requirements, finally yielding an effective integration of renewable generation. In the short term, however, the transmission network is predetermined to the existing infrastructure. Hence, the capacity of the existing transmission network may not be always sufficient to transport the requested amount of electrical energy. Congestion can occur, defined as a situation in which the requested transmission capacity exceeds the available capacity of the existing network.

In order to deal with this issue of limited transmission capacity, congestion management methods are developed to ease line overflows either using technical or economic procedures. Kumar et al. (2005) provide a literature survey on congestion management methods in deregulated electricity systems: technical measures aim to increase the capacity by adjusting load flows in the transmission network through specific devices (for example FACTS, phase-shifting transformers, switching of transmission lines), thereby avoiding changes in demand and generation. On the other hand, there are economic methods, relying on adjusting nodal feed-ins (nodal generation and/or demand) to reduce line overloadings. Those latter methods can be divided according to their timing within the market clearing process into preventive and curative methods. Preventive measures are applied before or during the clearing of the daily electricity markets whereas curative methods are applied after final market clearing. Explicit and implicit auctions are exemplary preventive congestion management methods and are applied, for instance, in central western Europe for allocating cross-border transmission capacity ${ }^{1}$, or in the US regional market of Pennsylvania-New Jersey-Maryland (PJM) ${ }^{2}$ using a nodal pricing approach. Curative congestion management includes the redispatch of power plants based on the final market commitments, and counter-trading. These methods are applied in most national electricity markets in Europe to manage internal congestion issues.

Regarding the economic evaluation of these management methods, de Vries and Hakvoort (2002) provide a study in which they show that preventive as well as curative congestion management measures are equally efficient in the short term perspective. Ding and Fuller (2005) analyze the economic effects of different pricing and congestion management regimes

\footnotetext{
${ }^{1}$ See http://www.epexspot.com/en/market-coupling

${ }^{2}$ See http://www.pjm.com/
} 
on the Italian electricity system. Their research shows that generation costs are identical among the investigated regimes, but the distribution of benefits and costs among market participants differs. Comparable analyses are performed in Kunz (2012) for the German and in Neuhoff et al. (2011) for the European electricity system. The latter two studies, in contrast to the previous analyses, identify cost benefits from adjusting congestion management regimes: as the redispatch of power plants is restricted to national units, higher congestion management costs are observed than in a perfectly coordinated nodal pricing regime. The issue of coordination in congestion management among different transmission system operators (TSOs) is further investigated in Oggioni et al. (2012). The authors develop a generalized Nash equilibrium model which is able to reflect different degrees of coordination among regional TSOs. It is applied in Oggioni and Smeers (2012) and Oggioni and Smeers (2013) to stylized electricity systems. It is shown that the degree of coordination in congestion management affects redispatch costs.

In this paper, we build on the equilibrium model developed in Oggioni et al. (2012). In order to investigate different degrees of coordination among German TSOs in conducting national congestion management, we suggest a new method of solving the arising class of problems based on multiplicatively decomposing the multipliers of shared constraints. Towards gaining numerical insights, we employ a detailed representation of the German electricity system covering the high-voltage transmission network, which is divided into four balancing zones each of which being managed independently by one of the four TSOs. Our results reveal that the level of coordination among the four German TSOs in mitigating national congestion in the transmission network impacts congestion management costs. While the considered cases are by construction identical in the spot market dispatch of power plants and hence the congestion pattern, they diverge in the utilization of available redispatching resources. In a setup with perfect coordination - implemented through one single TSO responsible for all zones - a least-cost redispatch can be achieved. In the restricted cases with imperfect coordination between multiple TSOs, the redispatching volumes and costs rise. This is particularly due to more expensive measures being required to ease overloadings in the transmission network.

The remainder of this paper is structured as follows: Section 2 introduces the economic redispatch model which captures the issue of coordinating congestion management among multiple TSOs. The developed model is applied to a dataset covering the German electricity system which is described in Section 3. We present our results in Section 4, and discuss them in Section 5. Finally, Section 6 concludes.

\section{The Model}

Our model consists of two stages: first, in the pre-stage, the electricity spot market is cleared by equalizing supply and demand in a cost-minimizing fashion without taking network limitations into account. Thereafter, in the main stage, plants and load are redispatched to correct for network infeasibilities that potentially may have emerged. Our focus lies on this main congestion management phase for which we analyze three cases: 
firstly, an unrestricted benchmark case with one single TSO being responsible for redispatch across all zones. Secondly, a restricted coordinated case with several TSOs, each of which being bound to resources within its own zone but in charge for network feasibility across all zones, and thirdly a restricted uncoordinated case where, again, TSOs are bound to own resources but are responsible for mitigating overflows only within their own zones. In all three cases, the two stages are not connected by any kind of feedback mechanism, the pre-stage is solely supposed to create a market-clearing dispatch that serves as data for the model's main stage.

\subsection{Pre-Stage: Market Clearing}

The power system consists of a set of nodes $\mathcal{N}=\left\{n_{1}, \ldots, n_{N}\right\} \ni n$ at each of which there is inelastic demand $q_{n}$ and deterministic injection of renewables - that is wind, solar and biomass - generation $g_{n}^{\text {res }}$. In this respect, the renewable technologies are assembled in $\mathcal{R}=\{$ Wind, Solar, Bio $\} \ni$ res. Residual demand is served by dispatchable plants $p \in \mathcal{P}=\left\{p_{1}, \ldots, p_{P}\right\}$ each of which being located at a certain node. Each conventional plant exhibits constant marginal generation costs $c_{p}$ and a maximum capacity of $g_{p}^{\max }$. For convenience, we abstract from further technical features such as minimum generation requirements, ramping constraints and so forth. Note that renewables generation is neither dispatchable nor subject to any uncertainty, but enters the model as deterministic data. Exports to or imports from neighboring countries are taken into account implicitly by adjusting our demand data (see Section 3). Mimicking the German market design, which features no explicit or implicit auctions of national transmission capacities, we model a uniform price across all nodes. Moreover, we assume perfect competition and the absence of any strategic behavior at the pre-stage: the market is cleared on a power exchange run by a single cost minimizing entity, dispatching generation $G_{p}$ for each plant, thereby equalizing supply and residual demand without taking the power network into account:

$$
\begin{aligned}
\min _{G_{p}} \sum_{p} c_{p} G_{p} & \\
G_{p} & \leq g_{p}^{\max } \\
\sum_{p} G_{p} & =\sum_{n}\left(q_{n}-\sum_{\text {res }} g_{n}^{\text {res }}\right)
\end{aligned}
$$

where $G_{p} \geq 0$. As the objective function (1) and the constraints (2), (3) are affine, the formulation constitutes an LP such that a solution is necessarily globally optimal. We denote the resulting dispatch of this pre-stage market clearing as vector $g=\left[g_{p_{1}} \ldots g_{p_{P}}\right]^{\prime} \ni$ $g_{p}{ }^{3}$

\footnotetext{
${ }^{3}$ Note that variables are denoted by capital letters, parameters by lowercase letters. Here, the pre-stage optimization result becomes data for the model's main stage.
} 


\subsection{Unrestricted Case: a Single TSO}

In the main stage of the model, the power network comes into play. In case the prestage market clearing outcome yields congestion on one or several lines, the TSO is in charge of relieving it. ${ }^{4}$ Note that the firms owning the generating units do not have any discretion here: according to German law they are obligated to execute the orders of the TSO whose grid they are connected to in case of network instability. ${ }^{5}$ As a benchmark, let a single TSO be responsible for congestion management within the whole system by optimally redispatching plants $p \in \mathcal{P}$, arranging load shedding or curtailing renewables generation at nodes $n \in \mathcal{N}$. Remember that each plant is associated to a specific node. In this respect, let the subset of all plants connected to node $n$ be rendered by $\mathcal{P}(n) \subset \mathcal{P}$. Denote the redispatched quantity at each plant $\Delta G_{p} \in \mathbb{R}$, the amount of load shedding at a node by $L S_{n} \in \mathbb{R}_{+}$, and the quantity of renewables curtailment for each node by $\operatorname{Cur}_{n}^{\text {res }} \in \mathbb{R}_{+}, \forall r e s \in \mathcal{R}$. Note that redispatched quantities at each plant can be positive or negative. In our model, we regard load and renewables curtailment as kinds of emergency measures which a TSO can draw upon in case the actual resources do not suffice. This interpretation is backed up by German law, which prescribes such actions as last resort to maintain system stability. ${ }^{6}$ Marginal generation costs at plant $p$ amount to $c_{p}$, as above, whereas one MW of load shedding costs $c^{L S}$, for wind, solar, and biomass curtailment $c^{r e s} \forall r e s \in \mathcal{R} .{ }^{7}$ The TSO's objective (4) consists in minimizing redispatching costs subject to several generation constraints: (5) prescribes that the overall changes in generation and load net out each other, whereas (6), (7) establish that generation at each plant $p$ may be no larger than its capacity limit $g_{p}^{\max }$, and nonnegative. Recall that $g_{p}$ represents the dispatched quantity from the market clearing stage. Restrictions (8), (9) ensure that load shedding and renewables curtailment at node $n$ is at most as large as demand $q_{n}$, or the produced quantities $g_{n}^{\text {res }}$ respectively. Network feasibility - the central issue of this problem - is expressed in condition (10): for each line $l$, the total flow, positive as well as negative, may be no larger than the line capacity $p_{l}^{\max }$. Loop flows are captured with help of the $\mathrm{PTDF}^{8}$ matrix, of which the $(l, n)$-element renders the fraction of the total flow

\footnotetext{
${ }^{4}$ Recall that overflows may solely originate from the pre-stage market dispatch that equalizes residual load and dispatchable supply. They do not emerge from any kind of uncertainty concerning renewables or load forecasts as demand and wind, solar, and biomass production enter the model as deterministic data.

${ }^{5}$ The legal basis is laid down in $\S \S 13.1,13.1$ a of the German Energy Industry Act (Energiewirtschaftsgesetz). Moreover, a regulation by the German Federal Network Agency BNetzA substantiates further operational guidelines, see BNetzA (2012b)

${ }^{6}$ The inclusion of such measures is in line with German law, which allows the non-injection of renewable generation under certain circumstances (see the German Energy Industry Act (Energiewirtschaftsgesetz), $\S 13.2,13.2 \mathrm{a}$, and the German Renewable Energy Act Erneuerbare-Energien-Gesetz, $\S \S 11,12)$, and also demand-side participation (see the German Energy Industry Act §13.2).

${ }^{7}$ The German Rebewable Energy Act $\$ 12$, stipulates that in case of renewables curtailment operators of the site get compensated for between $95 \%$ and $100 \%$ of their foregone profits. We quantify our cost parameter according to this regulation. The costs for the curtailment of demand are supposed to reflect the value of lost load and are set to $5000 \mathrm{EUR} / \mathrm{MWh}$.

${ }^{8}$ Power transfer distribution factor
} 
from node $n$ to a hub node through line $l$. Injection at a node $n$ is given by the sum of the generation of all plants at $n$, the redispatched quantity, renewables generation $g_{n}^{\text {res }}$ and load shedding quantity minus demanded quantity and renewables curtailment quantity. The TSO's constrained optimization problems thus reads as follows:

$$
\begin{aligned}
& \min _{\Delta G, L S, \text { Cur }} \sum_{p}\left[c_{p} \Delta G_{p}\right]+\sum_{n}\left[c^{L S} L S_{n}+\sum_{r e s} c^{r e s} C u r_{n}^{r e s}\right] \\
& \sum_{p} \Delta G_{p}+\sum_{n}\left[L S_{n}-\sum_{r e s} C_{u r}^{r e s}\right]=0 \\
& g_{p}+\Delta G_{p}-g_{p}^{\max } \leq 0 \quad \forall p \quad\left(\lambda_{p}^{1}\right) \\
& -g_{p}-\Delta G_{p} \leq 0 \quad \forall p \quad \forall p \quad\left(\lambda_{p}^{2}\right) \\
& -q_{n}+L S_{n} \leq 0 \quad \forall n \quad\left(\lambda_{n}^{L S}\right) \\
& -g_{n}^{\text {res }}+\text { Cur }_{n}^{\text {res }} \leq 0 \quad \forall n, \forall \text { res } \quad\left(\lambda_{n}^{\text {res }}\right) \\
& \left|\sum_{n} p t d f_{l, n}\left[\sum_{p \in \mathcal{P}(n)}\left(g_{p}+\Delta G_{p}\right)+\sum_{r e s} g_{n}^{r e s}-q_{n}+L S_{n}-\sum_{r e s} C u r_{n}^{r e s}\right]\right|-p_{l}^{\max } \leq 0 \quad \forall l \quad\left(\mu_{l}^{+,-}\right)
\end{aligned}
$$

where the multipliers in parentheses $\rho \in \mathbb{R}, \lambda_{p}^{1}, \lambda_{p}^{2} \in \mathbb{R}_{+} \forall p, \lambda_{n}^{L S} \in \mathbb{R}_{+} \forall n, \lambda_{n}^{\text {res }} \in$ $\mathbb{R}_{+} \forall n \forall r e s, \mu_{l}^{+}, \mu_{l}^{-} \in \mathbb{R}_{+} \forall l$ represent the shadow price of the respective constraint. The corresponding KKT conditions constitute a mixed linear complementarity problem:

$$
\begin{aligned}
& 0=c_{p}+\rho+\lambda_{p}^{1}-\lambda_{p}^{2}+\sum_{n \text { s.t. } p \in \mathcal{P}(n)}\left[\sum_{l} p t d f_{l, n}\left(\mu_{l}^{+}-\mu_{l}^{-}\right)\right] \perp \Delta G_{p} \text { free } \quad \forall p \\
& 0 \leq c^{L S}+\rho+\lambda_{n}^{L S}+\sum_{l} p t d f_{l, n}\left(\mu_{l}^{+}-\mu_{l}^{-}\right) \perp L S_{n} \geq 0 \quad \forall n \\
& 0 \leq c^{r e s}-\rho+\lambda_{n}^{r e s}-\sum_{l} p t d f_{l, n}\left(\mu_{l}^{+}-\mu_{l}^{-}\right) \perp C u r_{n}^{r e s} \geq 0 \quad \forall n, \forall r e s \\
& 0=\sum_{p} \Delta G_{p}+\sum_{n}\left[L S_{n}-\sum_{\text {res }} C u r_{n}^{r e s}\right] \perp \rho \text { free } \\
& 0 \leq-g_{p}-\Delta G_{p}+g_{p}^{\max } \perp \lambda_{p}^{1} \geq 0 \quad \forall p \\
& 0 \leq g_{p}+\Delta G_{p} \perp \lambda_{p}^{2} \geq 0 \quad \forall p \\
& 0 \leq q_{n}-L S_{n} \perp \lambda_{n}^{L S} \geq 0 \quad \forall n \\
& 0 \leq g_{n}^{\text {res }}-\mathrm{Cur}_{n}^{\text {res }} \perp \lambda_{n}^{\text {res }} \geq 0 \quad \forall n, \forall \text { res }
\end{aligned}
$$




$$
\begin{aligned}
& 0 \leq-p_{l}^{\max }+\sum_{n} p t d f_{l, n}\left[\sum_{p \in \mathcal{P}(n)}\left(g_{p}+\Delta G_{p}\right)+\sum_{r e s} g_{n}^{r e s}-q_{n}+L S_{n}-\sum_{r e s} C u r_{n}^{r e s}\right] \perp \mu_{l}^{-} \geq 0, \forall l \\
& 0 \leq-p_{l}^{\max }-\sum_{n} p t d f_{l, n}\left[\sum_{p \in \mathcal{P}(n)}\left(g_{p}+\Delta G_{p}\right)+\sum_{r e s} g_{n}^{r e s}-q_{n}+L S_{n}-\sum_{r e s} C_{u r}^{r e s}\right] \perp \mu_{l}^{+} \geq 0, \forall l
\end{aligned}
$$

Note that we have a linear objective function (4), and for (5) - (10) the linear constraint qualification holds. A solution for (11) - (20) is thus necessarily globally optimal.

\subsection{Restricted Cases: Multiple TSOs}

To expose the effect of coordination, in this subsection we divide the set of nodes into zones for each of which there exists one TSO solely able to manipulate quantities in its own zone. Each TSO is responsible to ensure its zonal system balance while he is restricted to the redispatching resources located in its zone. To this end, consider $T$ zones within each of which a single $t s o \in \mathcal{T}=\left\{t s o_{1}, \ldots, t s o_{T}\right\}$ is responsible for redispatching plants, or load shedding and renewables curtailment respectively. Note that each plant $p$ is associated to a specific node $n$, and each node to a specific TSO. Thus, denote the subset of all nodes within the zone of a TSO by $\mathcal{N}(t s o) \subset \mathcal{N}$, and recall the subset of all plants connected to a node $n$ being denoted by $\mathcal{P}(n) \subset \mathcal{P}$. Therefore, the set of all plants located within the zone of a certain TSO can be expressed as $\mathcal{P}(\mathcal{N}(t s o))$. However, the TSOs influence each other via the shared constrained of network feasibility on which the actions of all TSOs have an effect for all lines. Keep in mind that a TSO redispatching in its zone causes an effect not only within that zone, but - due to loop flows - alters flows on all lines in all zones. To represent this setup as a generalized Nash game, let $\Delta G_{t s o, p}, L S_{t s o, n}, C_{t s}^{r e s}, n$ denote the redispatched quantities of $t s o$ at plant $p$, the load shedding, and the renewables curtailment of tso at node $n$. Recall that the game is restricted insofar as manipulations at plants or nodes in a specific zone can only be undertaken by the respective TSO. The optimization problem again consists in minimizing redispatching costs under individual and shared constraints and for each player reads:

$$
\begin{gathered}
\min _{\Delta G, L S, \text { Cur res }} \sum_{p \in \mathcal{P}(\mathcal{N}(t s o))}\left[c_{p} \Delta G_{t s o, p}\right]+\sum_{n \in \mathcal{N}(t s o)}\left[c^{L S} L S_{t s o, n}+\sum_{r e s} c^{r e s} C u r_{t s o, n}^{r e s}\right] \\
\sum_{p \in \mathcal{P}(\mathcal{N}(t s o))} \Delta G_{t s o, p}+\sum_{n \in \mathcal{N}(t s o)}\left[L S_{t s o, n}-\sum_{r e s} C u r_{t s o, n}^{r e s}\right]=0 \quad \forall t s o \quad\left(\rho_{t s o}\right)
\end{gathered}
$$




$$
\begin{aligned}
& g_{p}+\Delta G_{t s o, p}-g_{p}^{\max } \leq 0 \\
& \forall p \in \mathcal{P}(\mathcal{N}(\text { tso })) \\
& \left(\lambda_{p}^{1}\right) \\
& -g_{p}-\Delta G_{t s o, p} \leq 0 \\
& \forall p \in \mathcal{P}(\mathcal{N}(\text { tso })) \\
& \left(\lambda_{p}^{2}\right) \\
& -q_{n}+L S_{n, t s o} \leq 0 \\
& \forall n \in \mathcal{N}(t s o) \\
& \left(\lambda_{n}^{L S}\right) \\
& -g_{n}^{r e s}+C u r_{t s o, n}^{r e s} \leq 0 \\
& \forall n \in \mathcal{N}(\text { tso }), \forall \text { res } \\
& \left(\lambda_{n}^{\text {res }}\right) \\
& \left|\sum_{n} p t d f_{l, n}\left[\sum_{p \in \mathcal{P}(n)}\left(g_{p}+\Delta G_{t s o, p}\right)+\sum_{r e s} g_{n}^{r e s}-q_{n}+L S_{t s o, n}-\sum_{r e s} C u r_{t s o, n}^{r e s}\right]\right|-p_{l}^{\max } \leq 0 \\
& \forall l, \forall t s o \quad\left(\mu_{t s o, l}^{+,-}\right)
\end{aligned}
$$

Constraints (22) - (26) take effect for each TSO separately. Also note that the shared constraint - here the network restriction (27) — is specific for each TSO as the dual variables $\mu_{t s o, l}^{+}$and $\mu_{t s o, l}^{-}$allow for an individual valuation of the respective constraints. Mathematically, however, this yields an underdetermined system in the way it is typical for generalized Nash games: identical constraints are valued differently by each player, therefore the problem consists of more free variables than distinct equations. To cope with that issue in an economically and mathematically sound manner, we modify the problem by assuming ex ante an exogenously different accounting of each player towards the shared constraints - introduced through a coefficient $\gamma_{l, t s o} \geq 0$. At the same time, we reduce the number of free variables by replacing the player-line-specific valuations $\mu_{t s o, l}^{-}, \mu_{t s o, l}^{+}$by only line-specific multiplier variables $\mu_{l}^{+,-}=\mu_{t s o_{1}, l}^{+,-}=\ldots=\mu_{t s o_{T}, l}^{+,-}$. In other words, we decompose the individual multipliers into a player-specific exogenous parametric part $\gamma_{l, t s o}$ and an endogenous multiplier $\mu_{l}^{+}, \mu_{l}^{-}$that is the same across all players, i.e. $\mu_{l, t s o}^{+}=\gamma_{l, t s o} * \mu_{l}^{+} \forall l$. As a result, we have as many equations as variables and the system can be solved. The relative valuation of the same shared constraint is pinned down exogenously by $\gamma_{l, t s o}$, motivated by theoretic considerations. The absolute level, however, is determined within the solution of the model in the multipliers $\mu_{l}^{+,-}$. Consequently, we replace (27) by (28):

$$
\begin{aligned}
& \gamma_{l, t s o}\left(\left|\sum_{n} p t d f_{l, n}\left[\sum_{p \in \mathcal{P}(n)}\left(g_{p}+\Delta G_{t s o, p}\right)+\sum_{r e s} g_{n}^{r e s}-q_{n}+L S_{t s o, n}-\sum_{r e s} C u r_{t s o, n}^{r e s}\right]\right|-p_{l}^{\max }\right) \\
& \leq 0 \quad \forall l, \forall t s o \quad\left(\mu_{l}^{+,-}\right)
\end{aligned}
$$

Observe that the shared network restriction (28) is multiplied with $\gamma_{l, t s o}$. The corresponding KKT conditions for (21) - (26) and (28) can be formulated as mixed linear 
complementarity problem: $\forall$ tso the following set of conditions has to hold:

$$
\begin{aligned}
& 0=c_{p}+\rho_{t s o}+\lambda_{p}^{1}-\lambda_{p}^{2}+\sum_{n \text { s.t. } p \in \mathcal{P}(n)}\left[\sum_{l} p t d f_{l, n} \gamma_{l, t s o}\left(\mu_{l}^{+}-\mu_{l}^{-}\right)\right] \perp \Delta G_{t s o, p} \text { free } \\
& \forall t s o, \forall p \in \mathcal{P}(\mathcal{N}(t s o)) \\
& 0 \leq c^{L S}+\rho_{t s o}+\lambda_{n}^{L S}+\sum_{l} p t d f_{l, n} \gamma_{l, t s o}\left(\mu_{l}^{+}-\mu_{l}^{-}\right) \perp L S_{t s o, n} \geq 0 \\
& \forall t s o, \forall n \in \mathcal{N}(t s o) \\
& 0 \leq c^{r e s}-\rho_{t s o}+\lambda_{n}^{r e s}-\sum_{l} p t d f_{l, n} \gamma_{l, t s o}\left(\mu_{l}^{+}-\mu_{l}^{-}\right) \perp C u r_{t s o, n}^{r e s} \geq 0 \\
& \forall t s o, \forall n \in \mathcal{N}(t s o) \\
& 0=\sum_{p \in \mathcal{P}(\mathcal{N}(t s o))} \Delta G_{t s o, p}+\sum_{n \in \mathcal{N}(t s o)}\left[L S_{t s o, n}-\sum_{r e s} C u r_{t s o, n}^{r e s}\right] \perp \rho \text { free } \\
& \forall t s o \\
& 0 \leq-g_{p}-\Delta G_{t s o, p}+g_{p}^{\max } \perp \lambda_{p}^{1} \geq 0 \quad \forall t s o, \forall p \in \mathcal{P}(\mathcal{N}(\text { tso })) \\
& 0 \leq g_{p}+\Delta G_{t s o, p} \perp \lambda_{p}^{2} \geq 0 \quad \forall t s o, \forall p \in \mathcal{P}(\mathcal{N}(t s o)) \\
& 0 \leq q_{n}-L S_{t s o, n} \perp \lambda_{n}^{L S} \geq 0 \quad \forall t s o, \forall n \in \mathcal{N}(t s o) \\
& 0 \leq g_{n}^{\text {res }}-\text { Cur }_{\text {tso }, n}^{\text {res }} \perp \lambda_{n}^{\text {res }} \geq 0 \quad \forall t s o, \forall n \in \mathcal{N}(t s o) \\
& 0 \leq \gamma_{l, t s o}\left(p_{l}^{\max }+\sum_{n} p t d f_{l, n}\left[\sum_{p \in \mathcal{P}(n)}\left(g_{p}+\Delta G_{t s o, p}\right)+\sum_{r e s} g_{n}^{r e s}-q_{n}+L S_{t s o, n}-\sum_{r e s} C u r_{t s o, n}^{r e s}\right]\right) \\
& \perp \mu_{l}^{-} \geq 0 \quad \forall l, \forall t s o \\
& 0 \leq \gamma_{l, t s o}\left(p_{l}^{\max }-\sum_{n} p t d f_{l, n}\left[\sum_{p \in \mathcal{P}(n)}\left(g_{p}+\Delta G_{t s o, p}\right)+\sum_{r e s} g_{n}^{r e s}-q_{n}+L S_{t s o, n}-\sum_{r e s} C u r_{t s o, n}^{r e s}\right]\right) \\
& \perp \mu_{l}^{+} \geq 0 \quad \forall l, \forall t s o
\end{aligned}
$$

As explained above ${ }^{9}$, in this generalized Nash game, we introduce different degrees of coordination between the players exogenously with help of the parameters $\gamma_{l, t s o}$ that

\footnotetext{
${ }^{9}$ Note that — as long as $\gamma_{l, \text { tso }}>0$ for some tuple $l, t$ so - (37), (38) do not lose or gain any information by being multiplied with $\gamma_{l, t s o}$ as the left-hand inequality can always be divided by that gamma. The different ex ante valuations, however, take effect in (30) - (32) where they represent tso's sensibility towards the constraint's multiplier.
} 
reflect the valuation of the shared network restriction of line $l$ by the respective TSO. In order to gain a convenient and concise representation, we collect these parameters in a $(L \times T S O)$-matrix $\Gamma=\left[\gamma_{l, t s o}\right]$. As an example, consider

$$
\Gamma=\left[\begin{array}{ll}
1 & 1 \\
0 & 1
\end{array}\right]
$$

In this case, $t s o_{1}$ and $t s o_{2}$ evaluate congestion on line 1 equally (first row), but $t s o_{1}$ does not take into account congestion on line 2 at all (second row). ${ }^{10}$ Recall that for each TSO the respective entry of $\Gamma$ is multiplied with the shared network feasibility constraint of line $l$. In case of a zero-entry, the TSO thus does not "see" the line in its optimization problem - see (37), (38).

For our analysis, we put forward two configurations of $\Gamma$. In version 'restricted coordinated' all TSOs are equally responsible for each line, which in turn implies that there exists coordination, for instance through a common market with the same shadow prices across all players. This is implemented for $\Gamma$ being a matrix of ones. In the case 'restricted uncoordinated' each TSO takes into account only lines within its own zone and those running between its zone and a neighboring one. The according columns of $\Gamma$ thus consist of zeros and ones at the respective entries. Recall that in any case each player's access is restricted to resources located in its own zone. Comparing our approach to the literature, Oggioni et al. (2012) analyze a similar Generalized Nash framework, but implement a solution technique following Nabetani et al. (2011), requiring certain technical assumptions to be fulfilled. Contrary to their approach of an additive decomposition of the individual multipliers for the common constraints, our multiplicative method provides an intuitive technique of implementing exogenous variations in the consideration of single lines by individual players. Moreover, our approach is capable to easily "switch off" the responsibility of players for specific constraints, i.e. lines, simply by the respective entry $\gamma_{l, t s o}=0$.

\section{Data}

The application of the described model covers the electricity system of Germany for the year 2011 with a detailed representation of the high-voltage transmission network. In the following subsections, we present our data sources as well as assumptions on transmission, generation, and load.

\subsection{Transmission}

We focus our analysis on the management of the German high-voltage transmission network including voltage levels of 220 and $380 \mathrm{kV}$. For convenience, we assume that there

\footnotetext{
${ }^{10}$ The entries of $\Gamma$ are generally not restricted to $\gamma_{l, t s o} \in\{0,1\}$, as we configure it in our application, but provide a high level of flexibility: for instance, the first row in the example could also be [2 1]. In that case, $t \mathrm{so}_{1}$ would value congestion on line 1 twice as much as $t \mathrm{so}_{2}$.
} 
are no grid losses. The topology of the network, comprising 342 substations and 866 transmission circuits, is based on ENTSO-E (2012b) and covers the balancing area of the four German TSOs 50Hertz, Amprion, TenneT TSO, and TransnetBW. The technical characteristics of the transmission circuits are based on Kießling et al. (2001) and include voltage specific values for resistance, reactance, and thermal transmission capacities. The respective values for resistance and reactance, accounted with the length of individual transmission circuits, provide the basis for the derivation of the power transfer distribution factors (PTDF). The PTDF matrix entails the information to which extent transmission lines are utilized by a nodal injection at a particular substation and is constant in time as we abstract from any changes in the network topology. Additionally, we derate the thermal transmission capacity by $20 \%$ to account especially for security requirements. ${ }^{11}$

In order to reduce computational complexity, we concentrate our analysis solely on the management of the German transmission system and abstract from direct interactions with neighboring countries. To this end, we treat the import and export with these countries as exogenous parameters. Moreover, this approach disentangles the effect of coordination between players within a system from potential re-optimizations in an NTCbased interaction between systems. The latter aspect is a main driver of results in Oggioni et al. (2012). To illustrate that point, consider two countries between which cross-border flows are subject to a net tranfer capacity (NTC). If this NTC does not entirely account for the available physical capacity, the interconnector might not be fully employed in the market dispatch. In such case, redispatching may occur, which is, however, then not driven by actual line congestion, but by re-optimization considerations. In constructing our grid topology and PTDF matrix, we take cross-border lines and lines within neighboring countries implicitly into account. To this end, we calculate a PTDF matrix for the whole central European network, and then cut off all nodes not located within Germany. We are left with virtual lines between those German nodes from which interconnectors run to adjacent countries. These virtual lines, inheriting the characteristics from the underlying actual lines in foreign countries, are represented by appropriate entries in our PTDF matrix.

\subsection{Generation}

On the generation side, we explicitly differentiate between conventional thermal generation, which can be dispatched at specified marginal generation costs, and non-dispatchable renewable generation, whose hourly level is given to the model as data and has to be fed into the grid. Thermal generation is considered on block level, and capacities as well as locations are based on BNetzA (2012c). It is assumed that generation facilities are connected to the nearest substation. In the course of the 2011 Fukushima incidents, the German government initiated to immediately shut down several old nuclear power plants.

\footnotetext{
${ }^{11}$ The resulting transmission reliability margin of 0.8 provides a conventional approximation of the $N-1$ criterion, see for example Leuthold et al. (2012).
} 
We thus also adjust our underlying generation portfolio accordingly starting from midMarch 2011. Generation facilities are characterized by their input fuel (nuclear, lignite, hard coal, gas, oil, hydro) and technology (steam process, gas turbine, combined cycle gas turbine). This information is used to calculate marginal generation costs based on fuel and emission costs, weighted by the power plant specific efficiency of the generation process. Table 1 summarizes the assumptions on fuel prices, reflecting the average price in 2011 (Statistik der Kohlenwirtschaft, 2013) - except for uranium and lignite which are based on own assumptions. To account for carbon emission costs, an average certificate price of 12.94 EUR per $\mathrm{t}_{\mathrm{CO}_{2}}$ is assumed, based on the EUA settlement price at the European Energy Exchange (EEX). The efficiency of the generation process depends on the process itself as well as the commissioning year of individual power plants (Schröter, 2004). Additionally, we impose an error term in the range of $0-0.01 \%$ on the derived efficiency to further differentiate plants in terms of marginal generation costs.

Table 1: Average fuel prices in 2011. Source: Statistik der Kohlenwirtschaft (2013) and own assumptions.

\begin{tabular}{lc}
\hline \hline & $\begin{array}{c}\text { Price } \\
\left.\text { [EUR/MWh } / \mathrm{Mh}_{\text {th }}\right]\end{array}$ \\
\hline Uranium & 3 \\
Lignite & 4 \\
Coal & 13.14 \\
Gas & 29.60 \\
Oil & 43.61 \\
\hline \hline
\end{tabular}

Beside thermal generation, renewable energies are taken into account comprising generation from wind, solar, and biomass. As renewables are considered to be non-dispatchable, we directly use the hourly total wind and solar generation of 2011 from EEX (2012). Concerning biomass facilities, we assume constant generation at available capacity. Total generation values of 2011 are depicted in Table 2. In order to derive a regional renewable generation pattern, the locations of renewable installations provided from $50 \mathrm{Hertz}$ et al. (2012a) are used as proxy. For simplicity and tractability reasons, we assume a perfect positive correlation of renewable generation across the model regions.

\subsection{Load}

The load entering our model is assumed to be price inelastic and thus fixed to the load values for each hour of 2011. Beside domestic load, exports to neighboring countries and pumping are included, whereas network losses are neglected. The hourly load pattern is based on the data published by ENTSO-E (2012a) and the German TSOs. Additionally, we upscale the demand pattern to be consistent with yearly load values reported in Eurostat (2013a). Similar to renewable generation, national load values need to be distributed to 
substations in the transmission network. Following Leuthold et al. (2012), we break down total hourly load according to regional GDP and population (Eurostat, 2013b). Our data for load in Germany represent original values for each hour of 2011 and are complemented by hourly export quantities (ENTSO-E, 2012a). Table 2 depicts the final demand on a yearly basis.

Table 2: Load and renewable generation in 2011. Sources: Eurostat (2013a) and EEX (2012)

\begin{tabular}{lc}
\hline \hline & $\begin{array}{c}\text { Yearly load or generation } \\
{[\text { TWh] }}\end{array}$ \\
\hline Load incl. exports and pumping & 542.8 \\
Total renewable generation & 94.7 \\
of which Biomass & 31.9 \\
of which Solar & 18.5 \\
of which Wind & 44.3 \\
\hline \hline
\end{tabular}

\section{Results}

We run the unrestricted model and both variants of the restricted model - restricted coordinated and restricted uncoordinated - on our dataset for all 8760 hours of the year 2011. In the following, we present our results on network overflows, as well as congestion management costs and volumes.

\subsection{Network Congestion from Spot Market Dispatch}

As a first step, we analyze which lines are subject to overload. Note that the geographical congestion pattern does not depend on the redispatch model, but is solely determined by the pre-stage market clearing outcome. Figure 1 visualizes our findings. Gray lines indicate that there is congestion on the line less than 500 hours, and black lines visualize overflows in more than 500 hours of the year 2011. Overall, out of 560 lines, 31 are subject to congestion in at least one hour, and 10 in at least one hundred hours. Among all 8760 hours, there are no overflows in 5236 hours, whereas in 3524 hours there is congestion on at least one line, and in 217 hours on at least five lines. The spatial pattern is generally in line with actual congestion reported by the German Federal Network Agency (BNetzA) monitoring report (BNetzA and BKartA, 2012): we reproduce frequent overflows on a line from Thuringia to Bavaria, in central Bavaria as well as in the northwestern region of Germany. Altogether, our model induces congestion on numerous lines and substations that are also mentioned in BNetzA and BKartA (2012) - however, it as well generates overflows in regions where it cannot be detected in the actual German 2011 data. In this respect, especially the western/south-western area has to be mentioned. 


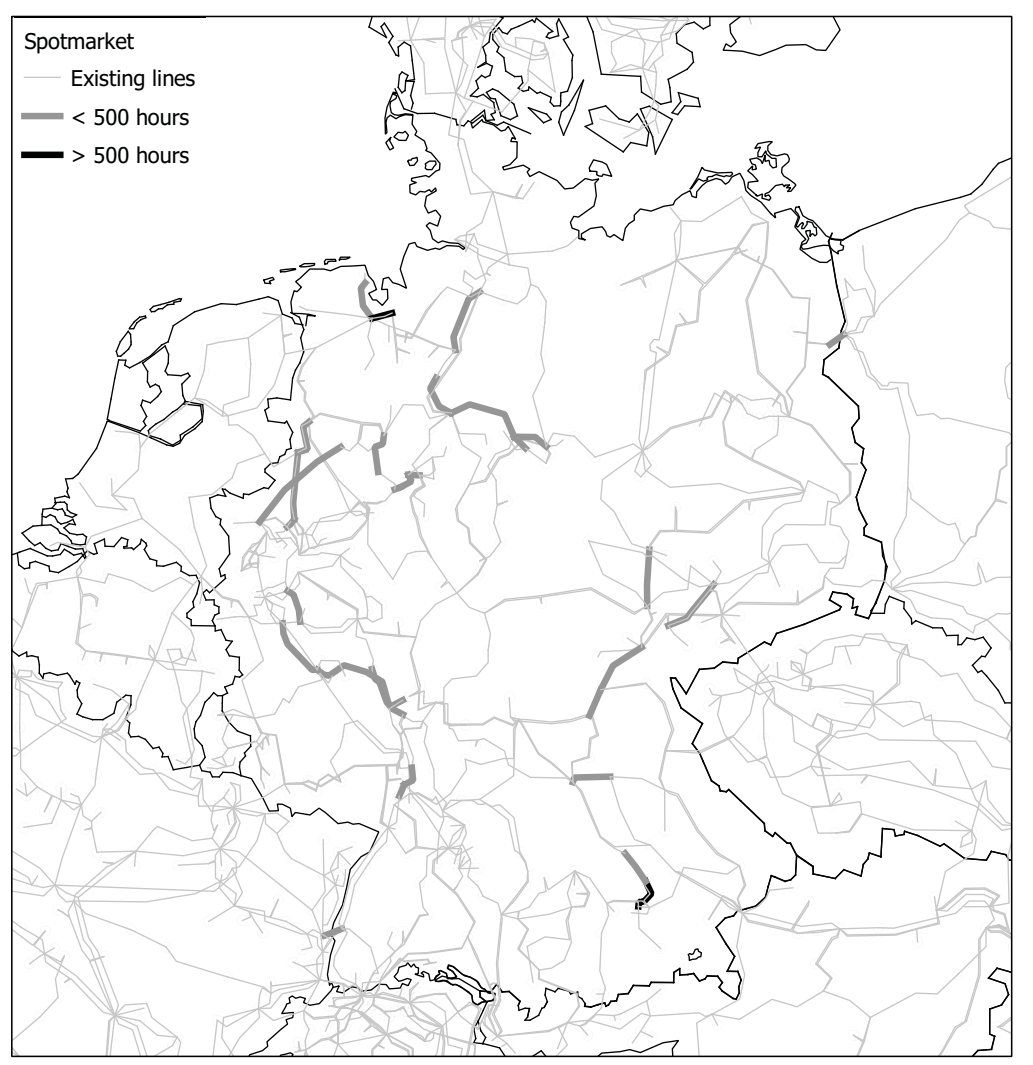

Figure 1: Spatial congestion pattern

Note, however, that among those lines several are included within the German Law on Network Expansion ${ }^{12}$ as prioritized measures to be pursued within a medium-run time frame. Also the German Network Development Plan of $2012^{13}$, which is compiled by the TSOs, assumes in its analyses those lines to be built in the nearer future. Thus, although there are some discrepancies between the congestion pattern our model detects and the actually observed pattern in the western/south-western region, those lines our model generates overflows on had been identified as prone to congestion by the actually responsible parties. Our findings (as well as the original 2011 data) represent a spatial dispersion within the German electricity system: the load centers in the south and southwest are remote from regions with excess generation, i.e. the eastern lignite and northern wind generation areas. This imbalance leads to a high level of flows on the relevant lines and, together with a high voltage grid not constructed to serve this needs, thus to congestion on the respective lines.

\footnotetext{
${ }^{12}$ Energieleitungsausbaugesetz (EnLAG), passed in 2009

${ }^{13}$ Netzentwicklungsplan 2012, see 50Hertz et al. (2012b, pp.209-279)
} 


\subsection{Redispatching Costs and Volumes}

We now turn to the results of the model's main stage and analyze the outcomes with respect to redispatching costs and volumes. To this end, we sum the absolute values of all, positive and negative, redispatch volumes as well as load and renewables curtailment instances, and denote this quantity as total volume. The redispatching costs can be stated as total and specific costs. Total costs describe the expenditures that accrue to a TSO for increasing generation plus compensation payments for load and renewables shed, reduced by the received payments from generators that decrease their generation level. In this respect, specific costs are calculated by dividing total costs by the total volume and can be interpreted as net payments per redispatched unit. Table 3 summarizes our findings.

Our central result is intuitive: total redispatching costs decrease with a higher degree of coordination. For the unrestricted model, redispatching costs amount to 8.7 million EUR, whereas for the restricted coordinated case, in which all TSOs are equally responsible for each lines but can only access own resources, they add up to 56.4 million EUR. This difference of roughly 47.7 million EUR can be attributed to coordination, for example by a common pool or market for redispatching resources. For the restricted uncoordinated model, where each TSO has access solely to own resources and moreover only takes care of congestion within its own zone, total redispatching costs amount to 138.2 million EUR. This difference of roughly 81.8 million EUR can thus be traced back to coordination, for instance through a common market for transmission capacity.

Table 3: Results for redispatching costs and volumes

\begin{tabular}{lc|cc}
\hline \hline Model & $\begin{array}{c}\text { Total } \\
\text { Volume } \\
{[\text { TWh] }}\end{array}$ & $\begin{array}{c}\text { Total } \\
\text { Costs } \\
\text { [mill. EUR] }\end{array}$ & $\begin{array}{c}\text { Specific } \\
\text { Costs }^{\mathrm{a}} \\
\text { [EUR/MWh] }\end{array}$ \\
\hline Unrestricted & 4.1 & 8.7 & 2.1 \\
Restricted Coordinated & 5.2 & 56.4 & 10.8 \\
Restricted Uncoordinated & 4.9 & 138.2 & 28.1 \\
\hline \hline \multicolumn{2}{c}{$\begin{array}{c}\text { For the restricted model variants, costs and volumes are summed over players. } \\
\text { Results are rounded to one decimal. }\end{array}$} \\
a Specific costs are calculated by dividing total costs by the total volume.
\end{tabular}

Concerning the redispatch volume, no such clear picture emerges: total yearly quantity is lowest for the unrestricted model with about $4.1 \mathrm{TWh}$, compared to $5.2 \mathrm{TWh}$ in the restricted coordinated model. Formally, this increase reflects the zonal energy balance see equation (22): if each of the four players, instead of one TSO across all zones, has to respect this constraint separately, each redispatch measure must be balanced within a zone. Thus, it is not possible that curative actions directly set each other off across zones in terms of the energy balance. To illustrate this "zonal balance effect", consider a line $l$ located in one zone and congested in direction west to east. A single TSO would, for example, lower generation at one plant at the western end of $l$ and increase generation of a 
plant located east to it by the same amount. If, however, there are multiple TSOs and the eastern plant lies in another zone, both measures would not set off each other any more to keep up the respective zonal balance, and further quantities within both zones would have to be activated. In the restricted uncoordinated model, the total redispatch volume amounts to 4.9 TWh, which is between the other cases: on the one hand, due to the lack of coordination, measures in one zone could lead to new congestion in other zones, driving the volume up compared to the unrestricted case. On the other hand, as foreign TSOs are not responsible for congestion within a player's own zone, the zonal balance effect is not active, which reduces the redispatching volume compared to the restricted coordinated case. $^{14}$

Moreover, there is a tendency to utilize more expensive redispatch resources. Costs per unit of redispatch rise from 2.1 EUR/MWh in the unrestricted single TSO benchmark, over $10.8 \mathrm{EUR} / \mathrm{MWh}$ for the restricted coordinated model, to 28.1 EUR/MWh in the restricted uncoordinated model. These high costs are mainly driven by a greater extent of load shedding. Figures 2 and 3 visualize how costs and volumes are distributed across redispatching measures, i.e. conventional plant redispatching, renewables curtailment and load shedding.

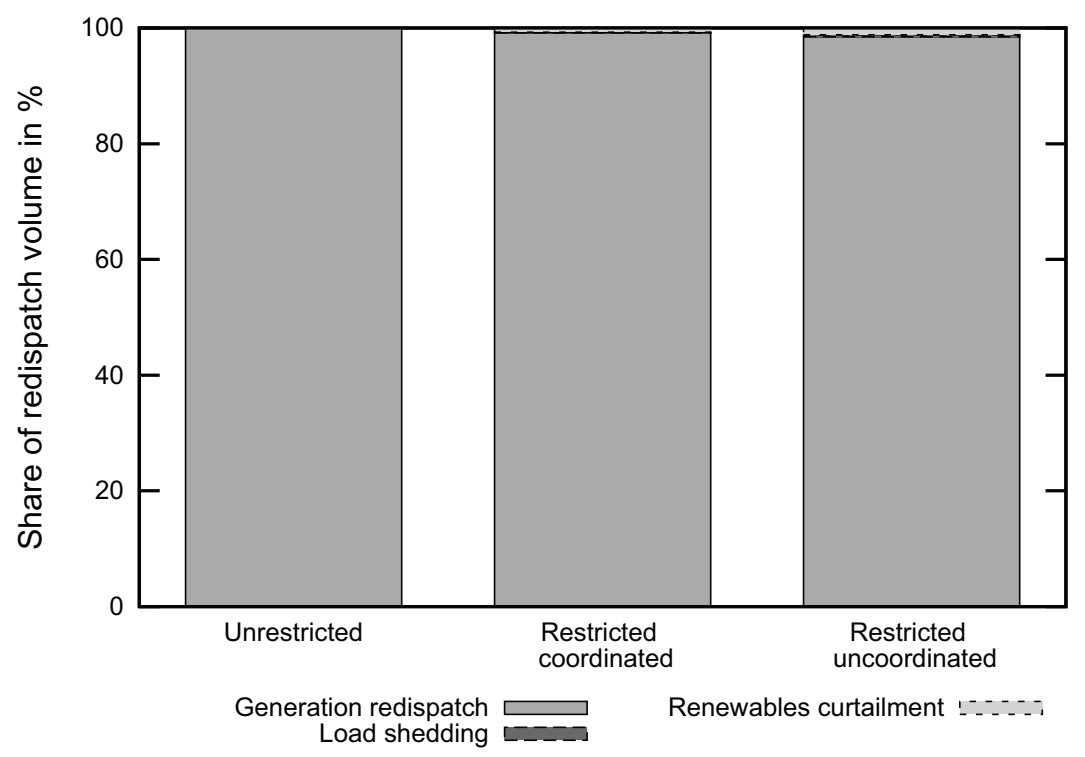

Figure 2: Redispatch volumes, broken down into technology shares

\footnotetext{
${ }^{14}$ Putting it abstract, assume the exemplary setup as in the text. Under the restricted coordinated regime, minimally four generation units are necessary to relief congestion while respecting zonal balances, whereas in the unrestricted case and restricted uncoordinated model, minimally two plants are necessary. In the latter case, moreover, plants in foreign zones will never be utilized.
} 


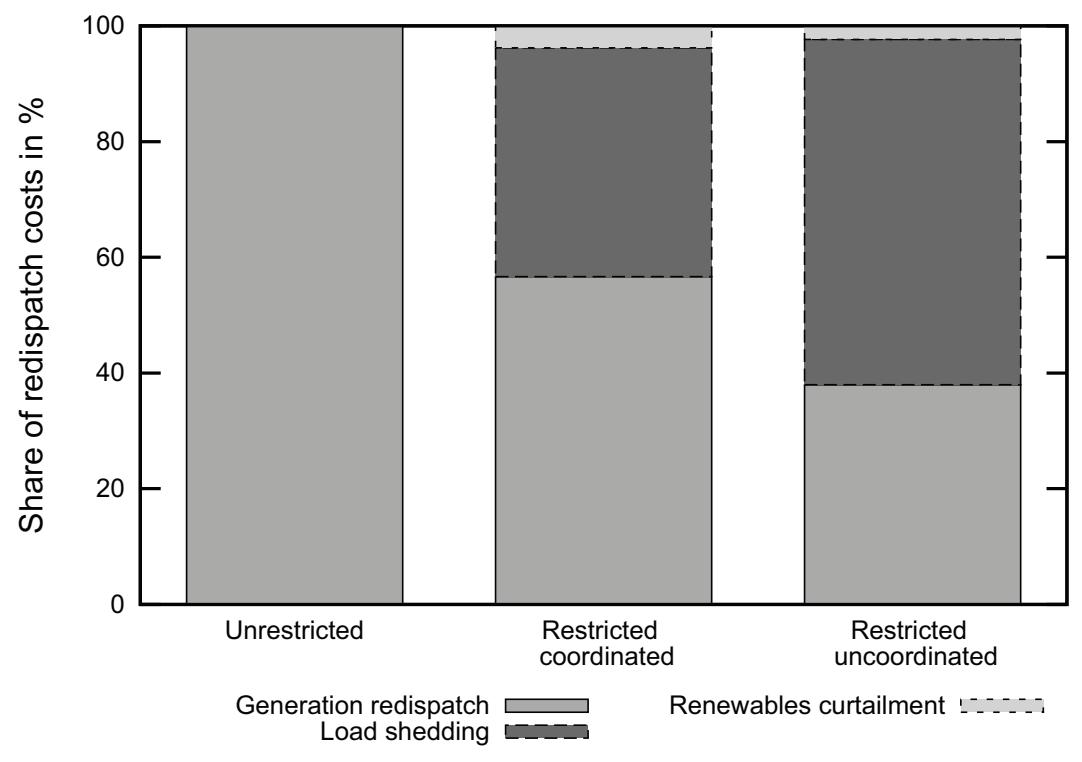

Figure 3: Redispatching costs, broken down into technology shares

As Figure 2 reveals, across the three models, the main fraction of the redispatch volume stems from changing plants' generation. Renewables curtailment and load shedding play only a minor role. The redispatching costs, which rise in absolute terms as coordination decreases, are mainly driven by the use of expensive load shedding, as visualized by Figure 3. While in the unrestricted single TSO case, total costs and costs per unit are low, the high specific costs for the restricted models can be attributed to the increasing share of load shedding measures. Note in this context, however, that the highest level of load shedding, occurring in the restricted uncoordinated model, does only comprise about 16.5 GWh, which represents about $0.003 \%$ of total yearly demand.

Summing up, the level of coordination among the four German TSOs in managing national congestion in the transmission network strongly impacts congestion management costs.

\section{Discussion}

While the considered cases are by construction identical concerning the initial spot market dispatch of power plants and hence the congestion pattern, they diverge in the utilization of available redispatching resources. In a setup with perfect coordination - i.e. one single TSO for all zones - the least-cost redispatch can be achieved. In the restricted cases with imperfect coordination between separate TSOs, redispatching volumes and associated 
costs rise. Particularly, this is due to more expensive redispatch measures being required to ease overloadings in the transmission network. Hence, our results reveal that congestion management costs increase substantially with a lower degree of coordination. Through the implementation of market mechanisms for redispatching resources as well as transmission capacity, transparent valuations of common constraints in terms of market prices are achievable, which have the potential to increase the degree of coordination. In the following subsections, we discuss several further perspectives on our model: we compare the setup and results with the actual situation in Germany, and analyze coordination benefits with respect to security issues, and network extension. Finally, we present a sensitivity analysis and comment on limitations as well as possible extensions.

\subsection{Degree of Coordination in Germany}

Relating our model setup and results to the current regime in Germany, we investigate which of our three model cases of inter TSO coordination resembles the prevailing situation closest. Basically, the underlying German legislation ${ }^{15}$ as well as its operationalization guidelines by the $\operatorname{TSOs}^{16}$ attribute the responsibility for relieving an overflow to that TSO in whose zone the congested line is located, which corresponds to our restricted uncoordinated case. In October 2012, the German Federal Network Agency (BNetzA) substantiated in a regulation that cross-zonal redispatch actions - may they be necessary to relief congestion that otherwise could not be removed or not - shall be coordinated between the affected TSOs (BNetzA, 2012a). Beside this short advisory formulation, however, no concrete coordination measures, procedures or entities are proposed or initiated. Concerning bilateral or multilateral agreements, we are aware of three such collaborations: firstly, the Security Service Centre (SSC) ${ }^{17}$, a cooperation initiative between the German TSO Amprion and the Dutch TSO TenneT, the latter being also one of the four players on the German market. SSC's goal consists in preparing common congestion forecasts and giving advice on coordinating measures. Moreover, the private entities Coreso $^{18}$, with a focus on western Europe, and TSC (Transmission System Operator Security Initiative) ${ }^{19}$, with a focus on central Europe, whose shareholders are TSOs from several European countries, provide coordinated network security analyses across and within countries. However their emphasis does not distinctly lie on the operational perspective of redispatching measures within Germany. ${ }^{20}$ Thus, the current situation in Germany basically resembles our restricted uncoordinated case although some coordination initiatives are actually implemented - however, not on a broad and comprehensively organized scope. ${ }^{21}$ Turning to the

\footnotetext{
${ }^{15} \S 13$ of the Energy Industry Act

${ }^{16}$ Laid down in the VDN Transmission Code 2007 (Verband der Netzbetreiber, 2007, pp.2-3, 37).

${ }^{17}$ See www. securityservicecenter.eu

${ }^{18}$ See www. coreso.eu

${ }^{19}$ See www.tso-security-cooperation.net

${ }^{20}$ For instance, in case a highly stressed network situation is predicted, inter TSO redispatch measures for Germany are also suggested as relief (Coreso, 2011, p.4)

${ }^{21}$ As a future perspective, the ENTSO-E Network Code on Capacity Allocation and Congestion Management shall pave the way for more international, and also German intra-national coordination of
} 
actually prevailed 2011 figures on congestion management in Germany, BNetzA (2012a, p.10) reports a redispatching volume of approximately $3.5 \mathrm{TWh}$, and total costs of more than 120 million EUR, yielding per unit costs of nearly $35 \mathrm{EUR} / \mathrm{MWh}$. Additionally, about $0.42 \mathrm{TWh}$ of renewables injection, mostly wind power was curtailed - reflecting roughly $0.9 \%$ of the total wind generation - causing additional costs of 33 million EUR (BNetzA and BKartA, 2012, p.59). Concerning the external validity of our approach, thus, our model outcomes resemble the actual numbers. There exist some differences, however, keep in mind that we have to pin down several modeling simplifications and assumptions. We discuss those issues in greater detail below.

\subsection{Impact of Demand-Side Participation}

In order to investigate how a voluntary participation of demand side measures influences redispatching costs, we vary the level of load shedding costs $c^{L S}$. Recall that in our main model specification they amount to $c^{L S}=5000 \mathrm{EUR} / \mathrm{MWh}$ and thus reflect the value of lost load in case demand has to be curtailed. A decrease to $300 \mathrm{EUR} / \mathrm{MWh}$ leads to a different interpretation: according to a recently specified regulation by the German Federal Government ${ }^{22}$ loads may in principle also participate as regular redispatch measures. In this context, a compulsory price range between $100 \mathrm{EUR} / \mathrm{MWh}$ and $400 \mathrm{EUR} / \mathrm{MWh}$ is specified. ${ }^{23}$ Conservatively assuming a price closer to the the upper limit, $c^{L S}=300$ EUR/MWh and re-running our model quantifies the extent of costs that could be saved by a comprehensive demand side participation in congestion management. Table 4 presents our results: for the unrestricted model, they stay virtually constant, whereas throughout the restricted model cases, total redispatching costs decrease compared with the basic model: in the restricted coordinated case, they amount to $52 \%$, and in the restricted uncoordinated case to $28 \%$ of the costs in the basic model layout. Specific costs, i.e. costs per unit, as well are lowered to $56 \%$ (restricted coordinated case), and $37 \%$ respectively (restricted uncoordinated case). The inclusion of demand side measures, thus, bears the potential for substantial cost savings.

\subsection{Implications for Security Aspects}

The removal of network congestion is ultimately necessary to provide security of supply. In this respect, lines that are loaded to the edge of their capacity constitute a risk: if unforeseen events occur, such as plant or line outages, it is ex ante unclear how overall network flows will be altered. However, the more lines are fully loaded, the more likely it is that one of those cannot accommodate a potentially increased flow on it, and the

redispatching measures. See ENTSO-E (2012c, p.29)

\footnotetext{
${ }^{22}$ Regulation on Dispatchable Loads ("Verordnung zu abschaltbaren Lasten" vom 28. Dezember 2012)

${ }^{23}$ See Regulation on Dispatchable Loads ("Verordnung zu abschaltbaren Lasten" vom 28. Dezember 2012), $\S 4.2$
} 
Table 4: Redispatching costs and volumes in case of demand side participation

\begin{tabular}{lcc|c}
\hline \hline & $\begin{array}{c}\text { Total } \\
\text { Volume } \\
\text { Model }\end{array}$ & $\begin{array}{c}\text { Total } \\
\text { Costs } \\
\text { [TWh }]\end{array}$ & $\begin{array}{c}\text { Specific } \\
\text { Costs }^{\mathrm{a}}\end{array}$ \\
\hline Unrestricted & 4.2 & 8.7 & 2.1 \\
Restricted Coordinated & 4.9 & 29.2 & 6.0 \\
Restricted Uncoordinated & 3.7 & 38.9 & 10.5 \\
\hline \hline
\end{tabular}

system is more prone to breakdowns. ${ }^{24}$ To assess the impact of coordination on security of supply, we compare the loading situation in our model results after the redispatch has been carried out. Figures $5-7$ in the appendix visualize the geographical pattern. In the unrestricted case, less lines are at the edge of their capacity than in the restricted cases: analyzing all 8760 hours, 19 lines are subject to being fully loaded for at least one hour in the unrestricted case, whereas this figure amounts to 25 in the restricted coordinated, and 29 in the restricted uncoordinated case. Also those lines which are at the edge of capacity are fully loaded in less hours in the unrestricted case than in the restricted cases. Moreover, the absolute number of load shedding or renewables curtailment interventions as well can be interpreted as a security indicator for network stability: according to $§ 13.2$ of the German Energy Industry Act, each such change can be classified as kind of a last resort measure in case redispatching of conventional power plants does not suffice to remove overflows. Comparing our model outcomes, in the unrestricted case no curtailments have to be carried out, in the restricted coordinated case 977 instances do occur, and in the restricted uncoordinated case this figure amounts to 3065. Therefore, the coordination of congestion management also implies a gain in network security by realizing the potential of decreasing the number of curtailment instances as well as lines at the edge of capacity.

\subsection{Implications for Network Expansion}

Theory suggests that congestion management can be seen as a substitute for physical network expansion in the long-run. To this end, suppose the existing lines do not suffice to serve the transmission needs in each hour: on the one hand, new lines can be erected in order to mitigate overflows, which comes at a specific cost. Alternatively, congestion can be managed by redispatching plants, which as well comes at a specific cost. Solving this tradeoff theoretically yields a cost-minimal combination of both measures, consider Figure

\footnotetext{
${ }^{24}$ In this context, keep in mind that we approximate the $N-1$ criterion by a transmission reliability margin of $80 \%$.
} 
4 that schematically depicts this issue. ${ }^{25}$ Obviously, the costs for capacity expansion are increasing in the amount of line capacity built (solid line), and the costs for congestion management decrease in overall line capacities. Here, we differentiate between high (upper dashed line), and low congestion management costs (lower dashed line), the latter as the result of a higher degree of coordination or as well demand side participation. Total costs are calculated as the sum of expansion and congestion costs and exhibit a U-shape (upper dotted and dashed lines). ${ }^{26}$

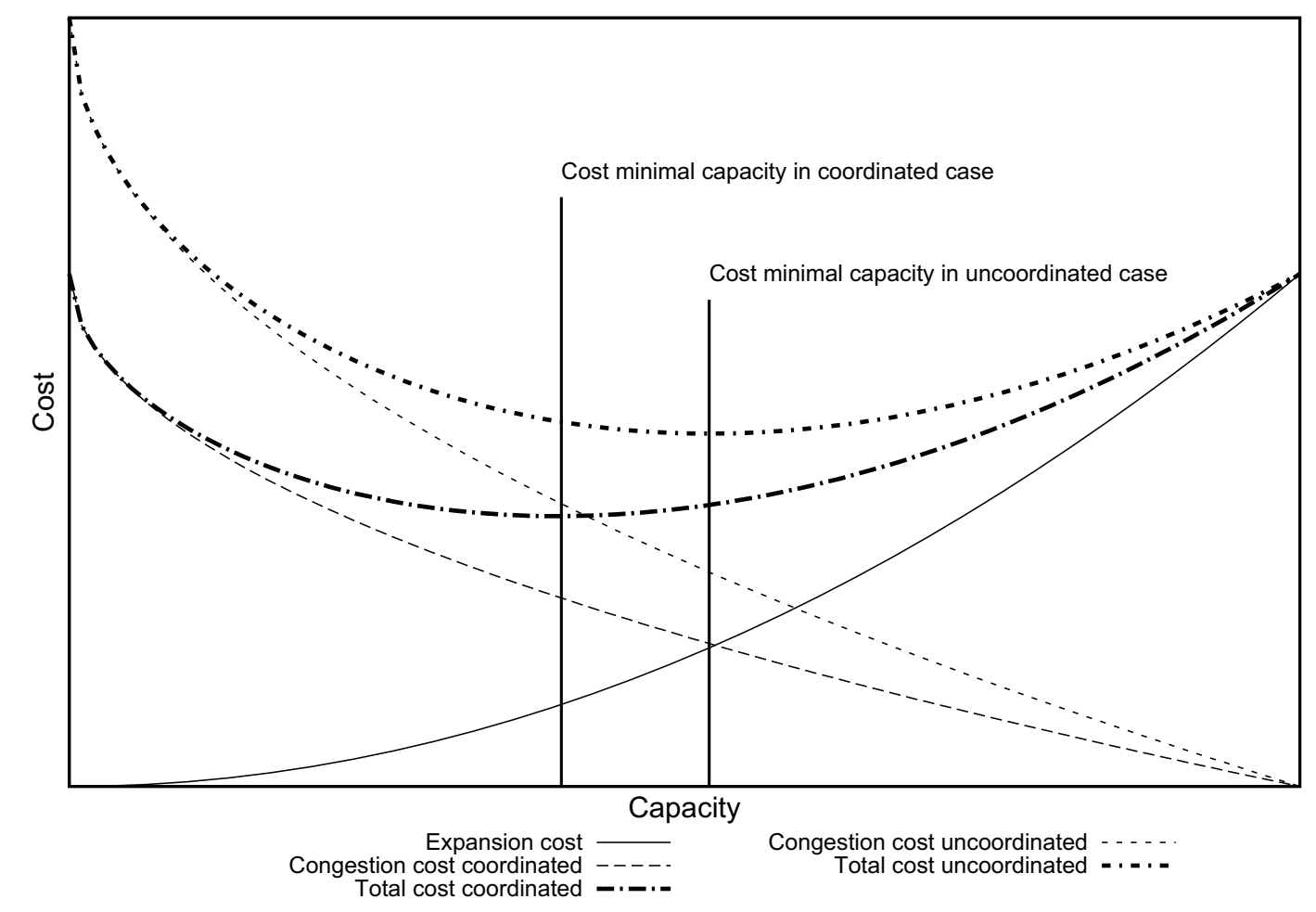

Figure 4: Tradeoff between capacity investment costs and congestion management costs

This schematic argumentation reveals that the minimum of total costs is achieved at a smaller line capacity in case of low congestion costs compared to the cost minimal line capacity for high congestion costs. Decreased congestion costs, for example induced by a higher degree of coordination, thus can have the effect that less line capacity has to be built in order to achieve the cost-minimal quantity. By pricing them in, the security

${ }^{25}$ For the tradeoff congestion management versus capacity expansion, see for example Kirschen and Strbac (2004, p.241), from which we as well took the graphical argumentation.

${ }^{26} \mathrm{It}$ is straightforward that the slope of the congestion management cost curves as a function of totally erected capacity is negative, for the capacity expansion costs curve positive. The exact curvature, however, is per se unclear. For brevity of the argument, however, we here assume the shapes to be as depicted. 
considerations discussed above also fit into this argumentation: coordinating redispatch yields a higher level of security. Without coordination, this same level could be achieved by employing more expensive measures, which would shift the congestion costs curve further up. Holding the level of security constant, thus, again less line capacity is necessary in case redispatching measures are coordinated. ${ }^{27}$

\subsection{Limitations}

Our model and its application is subject to several limitations. Presented results thus have to be interpreted taking these into account. First, the modeling abstracts from intertemporal decisions inherent to electricity systems such as endogenous dispatch of pump-storage facilities. Second, it is a pure dispatch model and henceforth does not take into account limitations of generation units through unit commitment restrictions, as for example minimum generation, online and offline time restrictions. Third, the determination of transmission flows is based on approximating an AC loadflow approach, and security aspects such as the $\mathrm{N}-1$ criterion are not considered in an explicit manner. Recall that we approximate these points, the $\mathrm{N}-1$ criterion as well as reactive power flows, by a reduction of the available transmission capacity to $80 \%$. Regarding the application of the model, outcomes are sensitive to input data. The data used here are based on publicly available sources, which entails that assumptions are required to break down national values on demand or renewable generation into regional levels. Specifically, the topology of the network is of particular importance as it determines lineflows and henceforth required congestion management actions. Furthermore, TSOs may also be able to accept temporary overloading of transmission lines or to adjust the network topology by switching actions which feeds back to congestion management costs. Kunz (2012) shows that this flexibility reduces congestion management costs substantially as flows in the transmission network can be partially controlled. In the presented application we abstract from these operational measures and assume a fixed network topology with defined transmission limits. Taking these aspects into account, it is per se unclear how results change: as further rigidities as well as flexibilities could be included, no clear-cut statement can be given in which direction results would change.

\section{Conclusions}

The German electricity system spawns a spatial load and generation pattern inducing network congestion in an increasing number of hours (BNetzA and BKartA, 2012). One reason consists in the "Energiewende", the reorganization of generation towards renewable sources, together with a high voltage grid not yet reconstructed to serve the emerging needs. As a short term curative method, the redispatching of power plants can be a relief to line overflows. In our paper, we explore whether the different TSOs, which is a

\footnotetext{
${ }^{27}$ Note, however, that firm inference would require a deeper discussion of that issue. Here, we stick to this brief sketch of the argumentation and leave a more detailed answer open for future research.
} 
constitutive feature of the German electricity system, can create benefits by coordinating congestion management actions.

To this end, we set up a model in which one single TSO is responsible for the costminimal redispatch of plants under the constraint of network feasibility, after a dispatch pattern has been created as input data in a market clearing pre-stage. Disaggregating this entity into several players in charge of the same task, each having the exclusive access to resources in its geographical zone, yields a generalized Nash equilibrium model in the fashion of Oggioni et al. (2012). Here, our methodological contribution lies in the ex ante attribution of responsibilities of TSOs to lines, formally introduced by a matrix of scalars $\Gamma$. This approach provides a formal procedure to reduce the number of endogenous multipliers for identical shared constraints. Motivated by economic considerations, we thereby induce solvability of an otherwise underdetermined system of equations, and set up a simple and applicable method to tackle generalized Nash equilibrium problems.

Applying this setup to detailed German data concerning lines, plants, hourly demand, and hourly renewables generation for the year 2011, we are able to quantify the benefits of coordinating congestion management: in case each TSO is responsible to relief overflows only within in its own zone with its own resources, which reflects the current situation in Germany closest, annual redispatch costs of 138.2 million EUR accrue. Coordinating the use of transmission capacities renders annual costs of 56.4 million EUR. As a benchmark, one single unrestricted TSO across all zones would have to bear redispatch expenditures of 8.7 million EUR. Moreover, the coordination of congestion management can yield a higher level of security and as well partially serve as a substitute for network expansion. In interpreting the results, however, there exist some caveats: our market clearing and redispatch model does not take into account several rigidities and flexibilities, such as ramping constraints, unit commitments or temporary line overloading. Specifically, numerical results are driven by the influence of costly load shedding emerging in the model's restricted cases. Nevertheless, we can conclude that coordination among the different players in charge of managing the power network has the potential for substantial cost savings.

\section{References}

50Hertz, Amprion, TenneT TSO, and TransnetBW (2012a): EEG Anlagenstammdaten, Internet: http://www.eeg-kwk.net/de/Anlagenstammdaten.htm, Accessed 09.01.2013.

50Hertz, Amprion, TenneT TSO, and TransnetBW (2012b): Netzentwicklungsplan Strom 2012, 2. berarbeiteter Entwurf, Internet: http://www.netzentwicklungsplan.de/ content/netzentwicklungsplan-2012-2-entwurf, Accessed 27.03.2013.

BNetzA (2012a): Beschluss BK6-11-098, Bundesnetzagentur (BNetzA), Internet: http://www . bundesnetzagentur.de/DE/Service-Funktionen/Beschlusskammern/ 1BK-Geschaeftszeichen-Datenbank/BK6-GZ/2011/BK6-11-001bis100/ 
BK6-11-098/BK6_11_098_Beschluss.pdf?_-blob=publicationFile\&v=2, Accessed 06.05.2013.

BNetzA (2012b): Beschluss BK8-12-019, Bundesnetzagentur (BNetzA), Internet: http: //www. bundesnetzagentur.de/DE/DieBundesnetzagentur/Beschlusskammern/ 1BK-Geschaeftszeichen-Datenbank/BK8-GZ/2012/BK8-12-019/BK8-12-019_ download.pdf?_-_blob=publicationFile, Accessed 27.03.2013.

BNetzA (2012c): List of Power Plants, Bundesnetzagentur (BNetzA), Internet: http: //www . bundesnetzagentur.de/cln_1932/EN/Areas/ElectricityGasRegulation/ SpecialTopics/PowerPlantList/PubliPowerPlantList_node.html; jsessionid= 79D374DC200620EB705734DCE17E6361, Accessed 09.01.2013.

BNetzA and BKartA (2012): Monitoringbericht 2012, Bundesnetzagentur (BNetzA) and Bundeskartellamt (BKartA), Internet: http://www. bundesnetzagentur.de/SharedDocs/Downloads/DE/BNetzA/Presse/Berichte/ 2012/MonitoringBericht2012.pdf?__blob=publicationFile, Accessed 11.04.2012.

Coreso (2011): Coreso Operational Review 2011, Internet: \{http://www.coreso.eu/ media/operational\%20review/Coreso_Operational_Review_2011.pdf\}, Accessed 25.04.2013.

Ding, F. and Fuller, J.D. (2005): Nodal, Uniform, or Zonal Pricing: Distribution of Economic Surplus, IEEE Transactions on Power Systems 20(2):875-882.

EEX (2012): EEX Transparency Platform, European Energy Exchange (EEX), Internet: http://www.transparency.eex.com/en/, Accessed 09.01.2013.

ENTSO-E (2012a): Consumption Data, European Network of Transmission System Operators for Electricity, Internet: https://www.entsoe.eu/data/data-portal/ consumption/, Accessed 09.01.2013.

ENTSO-E (2012b): Grid Map, European Network of Transmission System Operators for Electricity, Internet: https://www.entsoe.eu/publications/grid-maps/, Accessed 09.01.2013.

ENTSO-E (2012c): Network Code on Capacity Allocation and Congestion Management (Version 09/2012), European Network of Transmission System Operators for Electricity.

Eurostat (2013a): Regional Statistics by NUTS Classification (reg), Statistical Office of the European Union, Internet: http://epp.eurostat.ec.europa.eu/portal/page/ portal/region_cities/regional_statistics/data/database, Accessed 03.11.2011.

Eurostat (2013b): Supply, Transformation, Consumption - Electricity - Annual Data (nrg_105a), Statistical Office of the European Union, Internet: http://epp. eurostat.ec.europa.eu/portal/page/portal/statistics/search_database, Accessed 11.04.2012. 
Kießling, F., Nefzger, P., and Kaintzyk, U. (2001): Freileitungen - Planung, Berechnung, Ausführung, Springer Verlag, Berlin, Heidelberg.

Kirschen, D. and Strbac, G. (2004): Fundamentals of Power Systems Economics, John Wiley \& Sons, Ltd.

Kumar, A., Srivastava, S.C., and Singh, S.N. (2005): Congestion Management in Competitive Power Market: A Bibliographical Survey, Electric Power Systems Research 76(1-3):153-164.

Kunz, F. (2012): Improving Congestion Management - How to Facilitate the Integration of Renewable Generation in Germany, The Energy Journal forthcoming.

Leuthold, F.U., Weigt, H., and von Hirschhausen, C. (2012): A Large-Scale Spatial Optimization Model of the European Electricity Market, Networks and Spatial Economics 12(1):75-107.

Nabetani, K., Tseng, P., and Fukushima, M. (2011): Parametrized Variational Inequality Approaches to Generalized Nash Equilibrium Problems with Shared Constraints, Computational Optimization and Applications 48:423-452, Internet: http: //dx.doi.org/10.1007/s10589-009-9256-3, Accessed 30.01.2013.

Neuhoff, K., Boyd, R., Grau, T., Barquin, J., Echavarren, F., Bialek, J., Dent, C., von Hirschhausen, C., Hobbs, B., Kunz, F., Weigt, H., Nabe, C., Papaefthymiou, G., and Weber, C. (2011): Renewable Electric Energy Integration: Quantifying the Value of Design of Markets for International Transmission Capacity, DIW Berlin, Discussion Paper 1166, Internet: http://www.diw.de/documents/publikationen/73/diw_01.c. 387959.de/dp1166.pdf, Accessed 21.06.2012.

Oggioni, G. and Smeers, Y. (2012): Degrees of Coordination in Market Coupling and Counter-Trading, The Energy Journal 33(3):39-90.

Oggioni, G. and Smeers, Y. (2013): Market Failures of Market Coupling and CounterTrading in Europe: An Illustrative Model Based Discussion, Energy Economics 35:74-87, Internet: http://dx.doi.org/10.1016/j.eneco.2011.11.018, Accessed 07.01.2013.

Oggioni, G., Smeers, Y., Allevi, E., and Schaible, S. (2012): A Generalized Nash Equilibrium Model of Market Coupling in the European Power System, Networks and Spatial Economics 12:503-560, Internet: http://dx.doi.org/10.1007/s11067-011-9166-7, Accessed 07.01.2013.

Schröter, J. (2004): Auswirkungen des europäischen Emissionshandelssystems auf den Kraftwerkseinsatz in Deutschland, Master's thesis, Technische Universität Berlin, Institut für Energietechnik, Fachgebiet Energiesysteme, Internet: http://www.ensys.tu-berlin.de/uploads/media/schroeter_2004_auswirkungen_ co2_zertifikatehandel.pdf, Accessed 24.01.2013. 
Statistik der Kohlenwirtschaft (2013): Entwicklung ausgewählter Energiepreise, Internet: http://www.kohlenstatistik.de/files/enpr.xlsx, Accessed 27.03.2013.

Verband der Netzbetreiber (2007): Transmission Code 2007.

de Vries, L.J. and Hakvoort, R.A. (2002): An Economic Assessment of Congestion Management Methods for Electricity Transmission Networks, Competition and Regulation in Network Industries 3(4):425-466.

\section{Appendix}

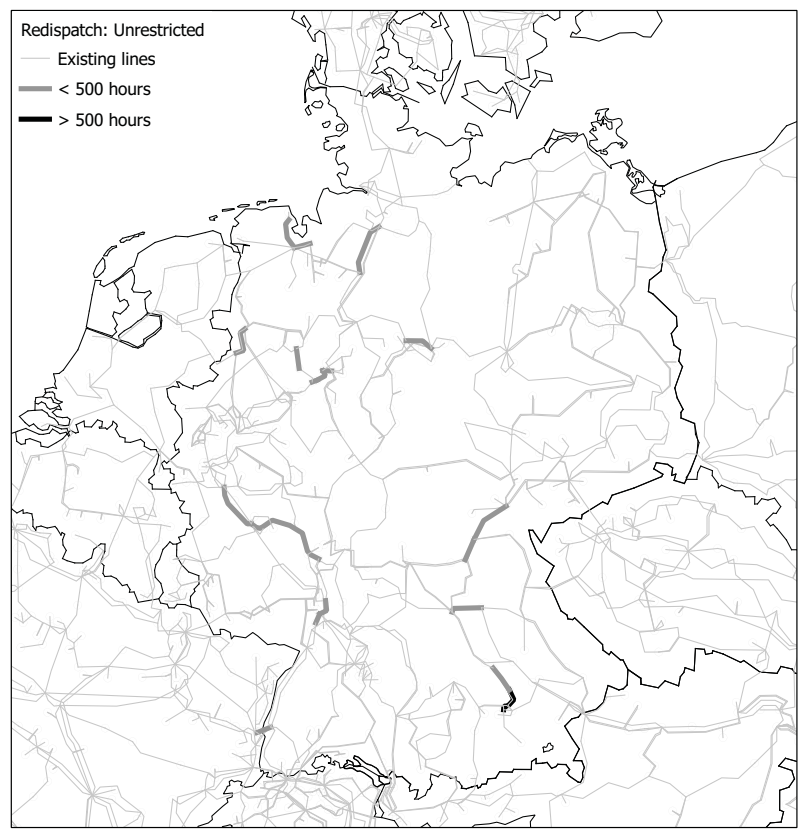

Figure 5: Unrestricted case: fully loaded lines after redispatch 


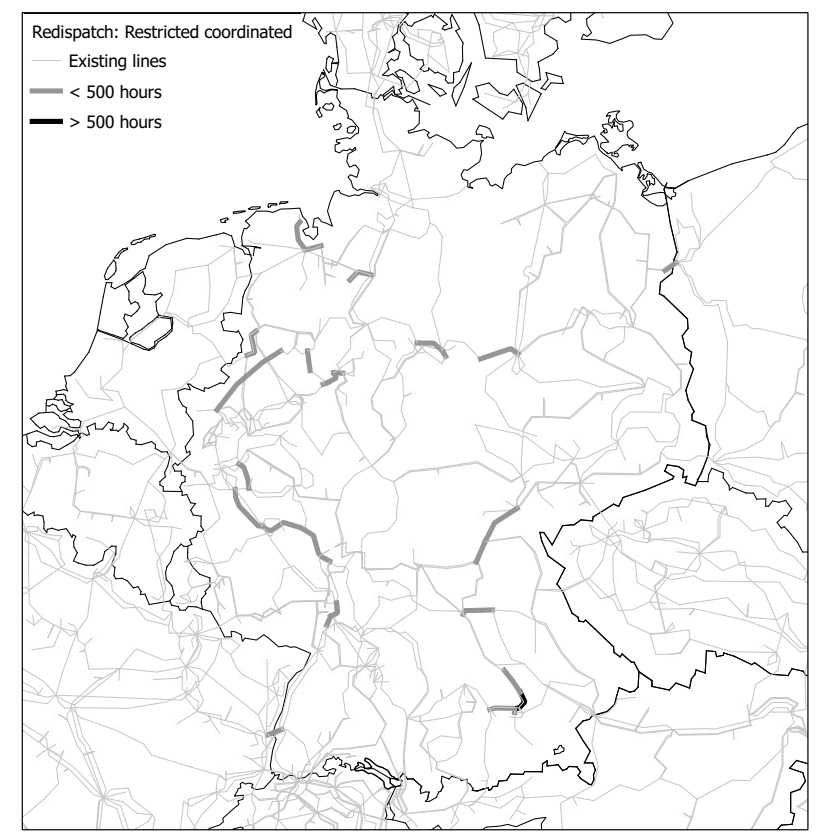

Figure 6: Restricted coordinated case: fully loaded lines after redispatch

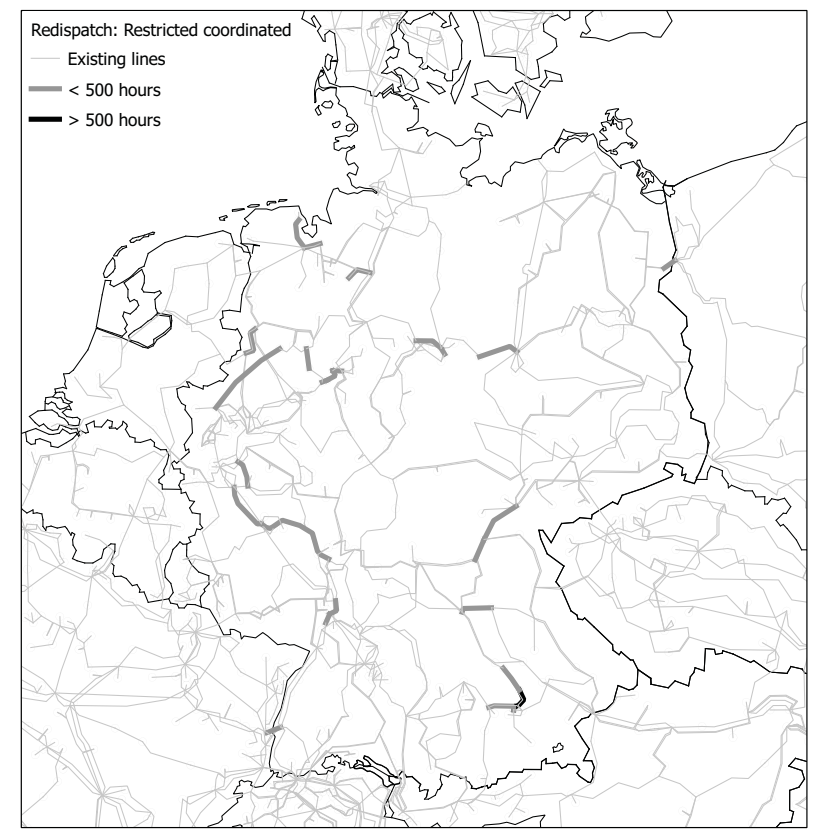

Figure 7: Restricted uncoordinated case: fully loaded lines after redispatch 